\title{
The Present Situation and Cause Analysis of Social Security Sense in Backward Areas
}

\author{
Ruan Mingyang \\ Kunming University, Kunming650214, China
}

Keywords: questionnaire survey; social security; backward areas; harmonious development

\begin{abstract}
With the overall improvement of social living standards, people's material level has been greatly improved, and they gradually began to care about the topic of social security. This paper makes a questionnaire survey and data analysis on the low social security sense of the backward areas, and find out the way to reduce the social security of people is the main problem of traffic safety, food safety, children's education and housing, and puts forward a series of solutions to solve these problems, it plays an important role in promoting the harmonious development of human society.
\end{abstract}

\section{Preface}

The rapid development of society, but also brought some security problems, reducing people's sense of security. Strengthening people's sense of security is the fundamental goal of the rule of law in the new era. People in the "risk society" are more than ever expected to be sheltered by the rule of law. Therefore, to study the significance of social security, social security from the people behind the status survey of the region, will carry on the analysis to reduce the public social security problems, and provide some basis for further research on social security.

\section{Sense of social security}

At present, the study of social security in China and abroad belongs to social investigation. Only the title or index does not distinguish the dimensions in the sense of psychology, therefore, this paper is mainly to study the different researchers for the understanding of the connotation of social security. Researchers at home and abroad will be content security is mainly divided into two categories: some researchers believe that social security is an emotional reaction accompanied by physiological changes, such as "subjective emotional reaction", "a fear caused by physiological changes, realized rapid heartbeat, high blood pressure," "on the social insecurity factors of negative emotions", "awareness of the potential dangers caused by fear"; another part of the study will be defined as a kind of social security comprehensive psychological reactions, such as "the social security situation of self perception and evaluation" and "of a certain time and space the destructive force of social security and control of subjective feelings, some researchers abroad also agree with this view, and that social security is mainly realized as a cognitive evaluation, emotional water Reactions, physiological and behavioral changes, etc..

As we all know, the concept of defining social security is not as complex as psychological security, and the debate about social security is only a discussion of whether it is merely an emotion".

The social security sense is defined as a comprehensive response researcher, and the cognitive assessment and behavior change are also included in the external extension of social security sense. But we can still see the essence of social security, the subjective experience of the individual study more impulsive, explicit, and this kind of experience will be affected by the social security situation, with the social situation changes. 


\section{Investigation and analysis of people's sense of social security in backward areas}

\subsection{Investigation on the social security sense of people in backward areas.}

In order to understand the current situation of social security in backward areas, this study conducted a questionnaire survey of social security sense in Libo County, Qiannan, Guizhou. In the study, 280 questionnaires were randomly distributed, 280 questionnaires were recovered, and 248 questionnaires were effective, with an effective rate of $88.6 \%$. In the questionnaire, the problems of "Do you think your life is safe?" and "Compared with the previous years, how do you feel about the security of your life?" were set up. In the first question, there are different options, such as "special security (4 points)", "comparative security (3 points)", "safety (2 points)" and "insecurity (1 point)"; In the second question, there are different options, such as "more secure (3 points)", "no change (2 points) " and" less safe (1 point)".

According to the survey results show that $76.9 \%$ of the villagers believe that their living environment is "safe" and "safe", among them, 58.1\% of the villagers think "special security", $18.8 \%$ of the villagers feel "safe", people's social security in the region. Average coefficient is 2.98, higher levels of Guizhou Qiannan province Libo county social security degree is strong. How do you change your sense of security in life over the past few years?" The problems in social security, think "safer" a total of 78 people, accounting for 31.4\%; think of social security for the "no change" a total of 56 people, accounting for 22.6\%; that social security "safer" a total of 114 people, accounting for $46 \%$; clearly, the residents of Libo county is part of a sense of security decreased.

\subsection{Analysis on the causes of low social security sense in backward areas.}

Through the statistical analysis of the questionnaire, the influence of Guizhou, Qiannan, Libo county social security mainly traffic safety, food safety, children's education and housing problems.

\subsubsection{Traffic safety problems}

In recent years, the rapid development of economy, people's living standards, the increase of income, transport has become the essential subjective impression, the number of private cars is increasing, in addition, the construction of a highly developed modern traffic, although the two to bring convenience, but also increase the security risks. According to the statistics from the Ministry of transportation, there are about 250 deaths per day in China, with an average of 10 deaths per hour. According to the statistics, the main reason for the villagers to answer "make you feel less social security" is?" In the problem, 104 people choose "traffic safety problem", accounting for 41.9\%, and a large part of the respondents believe that "traffic accident problem" is the most influential social security problem.

\subsubsection{Food safety issues}

Food safety is related to people's health and safety, people in recent years, countries pay more attention to food safety issues, in recent years the state has introduced new policies and regulations to regulate the food industry, is to let people eat at ease. However, with the rapid development of social economy, food safety problems also emerge in an endless stream, such as: Sanlu milk powder "and" Clenbuterol "," poison pepper "," poison ginger "," poison bean sprouts "and watermelons wine, ham sausage, with some negative event exposure, food safety sounded the alarm in the whole society. Now, our confusion is no longer "eat enough", "eat bad", but "eat unhealthy", "eat unsafe"'". According to the statistics, the main reason for the villagers to answer "make you feel less social security" is?" In the problem, there are 85 people who choose "food safety", accounting for 34.3\%. "Food safety problem" is the second problem that affects the sense of social security.

\subsubsection{Education for children}

With the global entering the new era of knowledge economy, the importance of education is gradually highlighted, the people's demand for education continues to improve. At present, China's education has entered the world's top level, but many people are faced with children's "difficult to enter the park", "school choice is difficult" and other practical problems. What is the main reason 
why the villagers are saying, "Do you think social security is low?"' In the problem, $20.3 \%$ of the village names believe that the issue of children's education has the most important influence on the sense of social security. It is generally believed that this problem mainly lies in the sharing of educational resources is not in place, the level of teaching staff construction in different regions and schools is too big.

\subsubsection{Housing problems}

In the eyes of the Chinese people, home is very important, and the house is the house of residence, the house is the basis of people's sense of security and happiness. In recent years, Chinese city urbanization fast, a large number of rural population into the city, increasing foreign population, housing the most basic needs to increase city commercial housing demand, which leads to the rigid demand the rapid rise in prices is also showing a rising trend, and many of the speculative real move, housing prices rose substantially and most people can not afford housing, greatly reduce the social security of residents.

\section{Strategies to improve people's sense of social security in backward areas}

\subsection{Strengthening traffic control inspection and punishment.}

In daily life, the main common causes of traffic accidents are as follows: (1) traffic facilities; (2) the road grade is low, the traffic condition is poor; (3) driving fatigue; (4) drunk driving; (5) speeding, overloading, illegal manned frequently; (6) no fault free parking; (7) the weather factors. In view of the above causes, the traffic control department should increase inspection efforts and severely punished illegal efforts, the specific measures are as follows: (1) to strengthen the education and management of motor vehicle drivers, improve safety awareness; (2) to strengthen the impact of climate on the traffic conditions, to do preventive work; (3) strengthen the management of key sections of time, eliminate hidden dangers of accidents; (4) to increase investment in science and technology, improve the ability to create a safe atmosphere of supervision at the source.

\subsection{Optimizing education layout and integrating educational resources.}

First of all, the role of government regulation, continue to increase investment in education, optimize resource construction, to increase efforts to support rural education, urbanization and actively create high-quality teachers, to keep up with the pace of development of rural education; secondly, efforts should be made to improve the rural teachers' salary and social status, the establishment of incentive and incentive mechanism, improve the rural teachers the salary and position, establish the corresponding incentive and punishment mechanism, promote the development of the rural education. Finally, focus on the development of public kindergartens, and actively encourage social forces to hold kindergartens, support inclusive private kindergarten.

\subsection{Strengthen the management of real estate, improve the proportion of affordable housing.}

Improving the living conditions of urban low-income residents is an important livelihood issue, and speeding up the construction of affordable housing projects is of great significance for improving people's livelihood and promoting social harmony and stability. House price is the most direct embodiment of the development status and development level of a city's real estate industry. The price must be with the economic and social development and income level of residents, housing prices are too high, beyond the consumption capacity of the residents, the real estate bubble formation, is not conducive to the healthy development of the real estate; price is too low, do not accord with the development of the real estate industry, is not conducive to the healthy development of real estate industry, but also caused the loss of government revenue. Therefore, the government should strictly examine and approve land system and regulate land use according to law. In addition, the government should vigorously develop affordable housing, take the initiative to assume the difference between the housing market price and residents' ability to pay. 


\section{Conclusion}

Social security is the low level of human needs, is one of the important indicators of the public evaluation of the effectiveness of social governance. With the change of the social situation, traffic safety, food safety, children's education and the residents of the housing problem gradually increased, the public social security brought many negative effects, and timely understanding of the public mind, has important significance to solve the problems of people's livelihood. The investigation and analysis from the people in backward areas of sense of social security is low, and puts forward some practical solutions to enhance people's sense of social security, promote the harmonious development of human society has an important role.

\section{Acknowledgements}

The work was supported by the construction project of Yunnan society, frontier and ecological environment research from Innovation team of philosophy and Social Sciences in Yunnan

\section{References}

[1] Li Wei. Analysis of the characteristics of China's public social equity evaluation in recent ten years [J]. Journal of Shandong University(Philosophy and Social Sciences), No.06, (2016), p.3-14.

[2] Zhang Yanxu. On the legal path to enhance the social security of [D]. Northeast Normal University, (2016).

[3] Lin Xiaoxiao. Causes and Countermeasures of house price rising [J]. Technological Development of Enterprise, Vol.35 (03) , (2016), p.127-128.

[4] Yang Mengting. Study on the influencing factors of public security in major natural disasters [D]. University of Electronic Science and technology of China, (2015).

[5] Peng Shanshan. Study on food safety supervision in China's rural market [D]. Guangxi Normal University, (2015).

[6] Song Baoan, Wang Yi. Interest balance mechanism and social security -- Based on the study of social security sense of urban and rural residents in Jilin province [J]. Study \& Exploration, No.03, (2010) , p.106-112.

[7] Zhao Yandong, Wei Jianwen. Research on the relationship between social capital and public social security sense in Western China [J]. Research on Letters and Calls and Social Contradictions \& Problems No.03, (2013), p.62-74.

[8] Chen Jianhui. Philosophical thinking on the sense of security [D]. Xiangtan University, (2013).

[9] Zeng Fanshe. A study on the influence of psychological safety factors on chemistry experiment of community students [D]. Shandong Normal University, (2013).

[10] Tian Junfeng, Wang Binyan, Lining. Changchun city residents sense of social security research [J]. Economic Research Guide, No.09, (2013) , p.175-179.

[11] Zhuang Haiqing. Application of structural equation model in the investigation of urban residents' social security sense [D]. Hunan Normal University, (2013).

[12] Zhao Ling. Study on Chinese urban public security during the transition period [D]. Fudan University, (2013).

[13] Zheng Chanjuan, Feng Yun. The public sense of security will decline and the rural areas should be the focus of attention [J]. Marketing Research, No.12, (2009) , p.19-20.

[14] Yao Benxian, Wang Haibin. Research on the concept of security from the perspective of integration [J]. Jianghuai Tribune, No.05, (2011) , p.149-153.

[15] Wang Li, Pan Yiping, Li Wen, Li Mingxin, Liu Yuting. Investigation and analysis of public social security status, [J]. Times Finance, No.23, (2011) , p.151-152.

[16] Zhang Junhao. Study on the efficiency of food safety supervision based on property rights theory [D]. Wuhan University, (2011). 